\title{
Grid Synchronisation of Photovoltaic Distributed Generation Using Hybrid FUZZY-PI Controller
}

\author{
B.G Sujatha, Anitha G.S
}

\begin{abstract}
The power generation of the world has to be increased every year as the demand increases rapidly. The high power generations are done by hydro, thermal and atomic. The power production cant is increased every year as the cost of power production increases due to this constraint and increase in high power generation increases pollutions. So the distribution side generation are used, and the PV based power generations are used mostly as the maintenance is less comparatively. The power control in $P V$ power generation is done by $D Q$ technique which is most widely used. It has a PI controller to regulate the real power. In this paper, the fuzzy logic control which is combined with the PI controller is used to increase the controllability of the power system. The MATLAB $2017 \mathrm{~b}$ is used to do the simulation of the applied technique and the results are discussed with improvements.
\end{abstract}

Keywords: Hybrid FUZZY-PI Controller, Distributed Generator, Grid Synchronization, Photovoltaic Generator, d-q technique

\section{INTRODUCTION}

The Power generation of distributed generation is one of the needs in the recent increase in power demand. In distributed generations, PV power plants are in the view of the researchers as it is less in maintenance. The PV power generations needed the Maximum Power Point Tracking (MPPT). There many techniques available but the most simpler algorithm is $\mathrm{P} \& \mathrm{O}$ technique. This helps to track the maximum power always. Then the $\mathrm{PV}$ power generation is $\mathrm{DC}$ and the utility is an AC. So there is a need for an invention of $\mathrm{DC}$ to $\mathrm{AC}$ for making it useful in the utility the power control is required. The direct and quadrature axis control or DQ or decoupled controller is used to do the conversion, where the DC link voltage is controlled to control the real power. The reactive power is taken as zero to maintain a unity power factor.

Many kinds of literature are discussing the concept which is given in the above paragraph. The big data analysis concept implication in PV power generation is done in [1]. And detailed literature review is carried out in [2] for modelling of the PV power plant. The performance modelling of PV is done in [3] for ensuring large power generation is discussed. The control of the PV power is discussed in [4] the large scale

Revised Manuscript Received on November 05, 2019.

* Correspondence Author

B.G.Sujatha*, Phd Student, Jain University, Bangalore, India. Email: sujatha_sudhir@yahoo.co.in

Dr. Anitha G.S , Electrical and Electronics Engineering Department, R.V College of Engineering, Bangalore, India. Email: xyz2@blueeyesintlligence.org power system with more penetration of renewable power generation. The virtual energy storage concept is presented in [5]. This is used for power demand compensation with voltage regulation. The dynamic voltage statbility is discussed in [6] with grid tied with PV. The different MPPT techniques performance analysis is discussed in [7]

The fuzzy logic is used in PV based grid connection control which is using Z-source inverter is discussed [8]. It is helpful in boosting the voltage. Fuzzy based PI tuning is done in [9] and a literature review of fuzzy implementions are discussed in [10]. The power oscillation statblity and disturbance reductions and THD improvement of PV connected to grid is discussed in this paper. And also performance improvement by the PI controller which is replaced with fuzzy-PI is also presented. The upcoming sections discusses about PV mathematical model, MPPT techniques and Current controller with PI and fuzzy-PI with the results and discussion.

\section{PV MATHEMATICAL MODEL WITH CONTROLLER}

The single diode PV cell mathematical model is used in this paper that is depicted in the Figure 1.The model is a current source with a diode in parallel with a series and a parallel resistors to indicate the $\mathrm{PV}$ cell model.

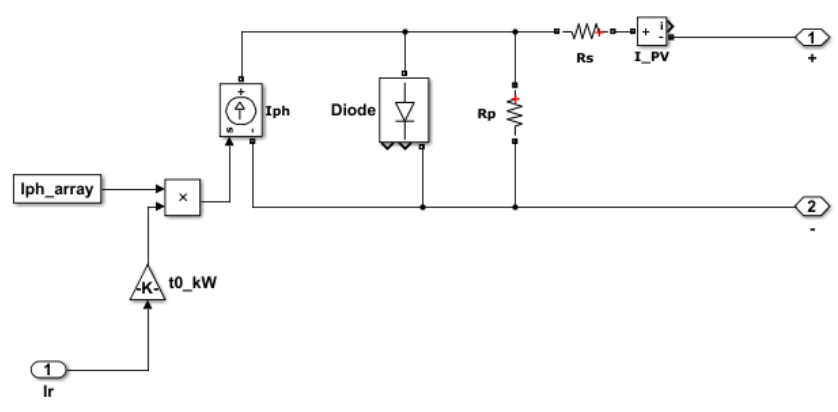

Fig. 1.PV cell mathematical model

Diode characteristic equation

$I_{d}=I_{\text {sat }} \times \mathrm{e}^{\left(\frac{V_{d}}{V t}-1\right)}$

Where,

$I_{d}$ - diode current in $A$

$V_{d}$ - diode voltage in $V$

$I_{\text {sat }}$ - diode saturation current in $\mathrm{A}$

$V_{t}-$ temperature voltage

Here,

$V_{\mathrm{t}}=\frac{k \times T}{\mathrm{q} \times \mathrm{Q}_{\mathrm{d}} \times \mathrm{N}_{\mathrm{cs} \mathrm{II}} \times \mathrm{N}_{\mathrm{szr}}}$

$T$-cell temperature in $K$

$k$ - Boltzman constant

$q$-electron charge 
$Q_{d}-$ diode quality factor

$N_{\text {cell }}-$ number of series connected cells per modules

$N_{\text {ger }}-$ number of series connected modules per strings

\section{A. Perturb and Observe MPPT Controller}

One of the most common hill-climbing methods is $\mathrm{P} \& \mathrm{O}$ algorithm. The hill-climbing by the name also refers to $\mathrm{P} \& \mathrm{O}$. The perturbation of the duty cycle in a BOOST converter and a change in the voltage at the DC-link between the PV array and the BOOST converter both are called as hill-climbing. The perturbation in the duty cycle of the BOOST converter changes the voltage at the DC-link. By perturbing the duty cycle and observing the power output is done in this algorithm. The sign of the measured voltage and the sign of the power measurement decide the perturbation in the duty cycle. Figure 2 depicts the voltage with the current characteristic (a) and power with voltage characteristics.

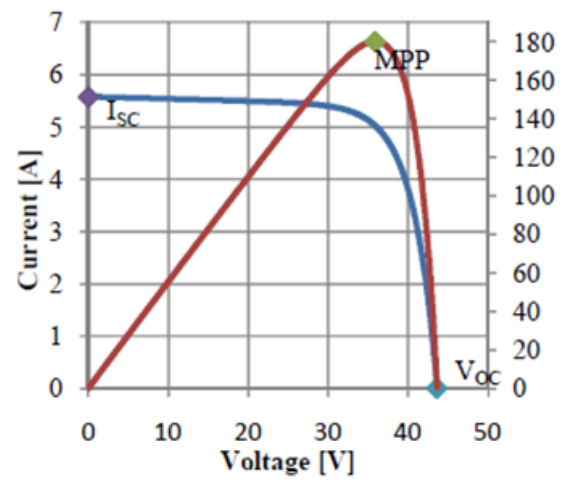

(a)

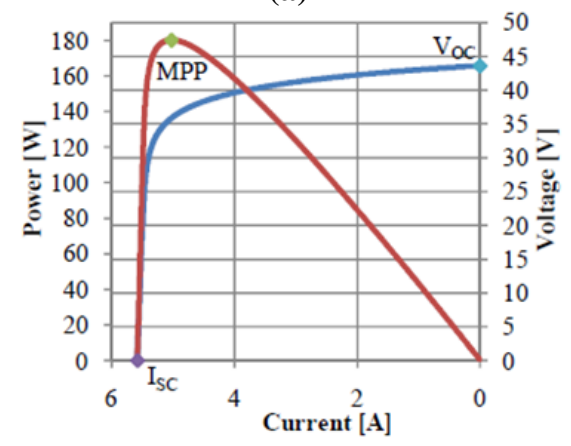

(b)

Fig. 2.(a) Voltage vs Current (b)Power vs Voltage Characteristics of the PV array

If there is no change in voltage and power then no variation in the duty cycle will be observed according to the $\mathrm{P}$ and $\mathrm{O}$ algorithm. When the change in voltage in + sign and power also in + sign then the duty cycle increases to check the next sample. If the change in voltage is in + sign and the change in power in - sign then decrease the duty cycle. And if both are in - sign then increase the duty cycle. If the change in voltage is - sign and change in power in + sign then decrease the duty cycle as depicted in the flowchart shown in Figure 3.

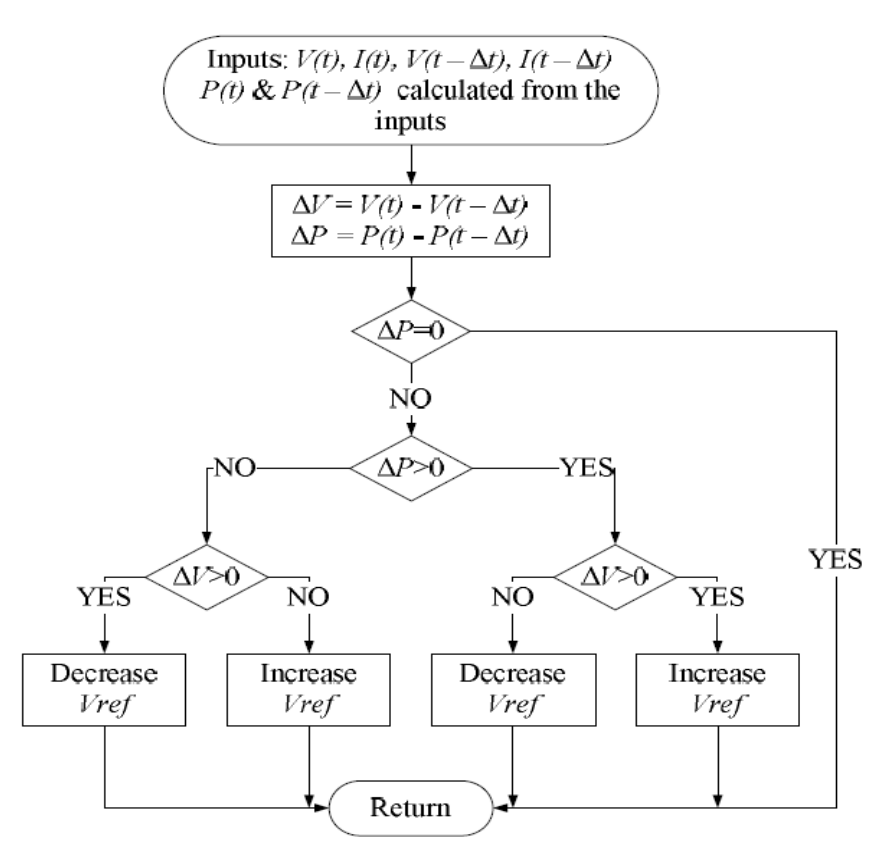

Fig. 3.Perturb \& Observe (P\&O) algorithm

The voltage and current at time instants $t$ and $t+\Delta t$ are received from the PV array and the perturb and observed algorithm is developed using the flowchart defined in the Figure 2.

\section{B. DQ Controller for Grid Synchronisation}

The direct axis and quadrature axis components of the voltage and current waveforms are received from the grid side and the inverters side and these orthogonal components are used for the decoupled control which leads to grid synchronization. The independent control of the orthogonal components in the DQ controller leads to the grid synchronization of the PV based DG to be connected to the grid. The three phase voltage and current is orthogonally transformed as given in the equation (3) in order to realize the decoupled control action. This is called the Park's transform and it would deliver a decoupled controller.

$$
\left[\begin{array}{l}
u_{d} \\
u_{q} \\
u_{0}
\end{array}\right]=\frac{2}{3}\left[\begin{array}{ccc}
\cos (\omega t) & \cos \left(\omega t-\frac{2 \pi}{3}\right) & \cos \left(\omega t+\frac{2 \pi}{3}\right) \\
-\sin (\omega t) & -\sin \left(\omega t-\frac{2 \pi}{3}\right) & -\sin \left(\omega t+\frac{2 \pi}{3}\right) \\
\frac{1}{2} & \frac{1}{2} & \frac{1}{2}
\end{array}\right]\left[\begin{array}{l}
u_{a} \\
u_{b} \\
u_{c}
\end{array}\right]
$$

While similarly after the dq control action creates the reference direct and quadrature components they are again converted back from dq frame to three phase references. This can be achieved using the inverse Park's transformation as defined in equation (4).

$$
\left[\begin{array}{l}
u_{a} \\
u_{b} \\
u_{c}
\end{array}\right]=\left[\begin{array}{ccc}
\cos (\omega t) & -\sin (\omega t) & 1 \\
\cos \left(\omega t-\frac{2 \pi}{3}\right) & -\sin \left(\omega t-\frac{2 \pi}{3}\right) & 1 \\
\cos \left(\omega t+\frac{2 \pi}{3}\right) & -\sin \left(\omega t+\frac{2 \pi}{3}\right) & 1
\end{array}\right]\left[\begin{array}{l}
u_{d} \\
u_{q} \\
u_{0}
\end{array}\right]
$$

In both the equations u denotes both current and voltage. 


\section{DC link Voltage Controller}

For a steady state working of the three phase inverter connected to the grid the DC link voltage should be maintained constant for proper synchronization. The PI controller to develop the reference that is included in the direct axis reference is considered. The difference between the actual and the reference DC link voltage is

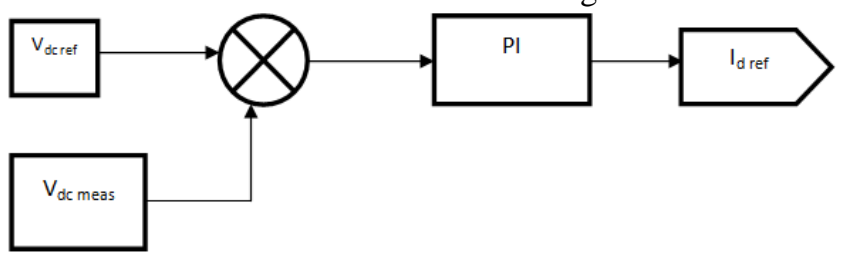

Fig. 4.DC link voltage controller

DC link set point is set for with $V_{\text {de ref }}$ the $V_{\text {de meas }}$ is subtracted and the error is minimized by PI regulator by sending $I_{d \text { ref }}$ as output.

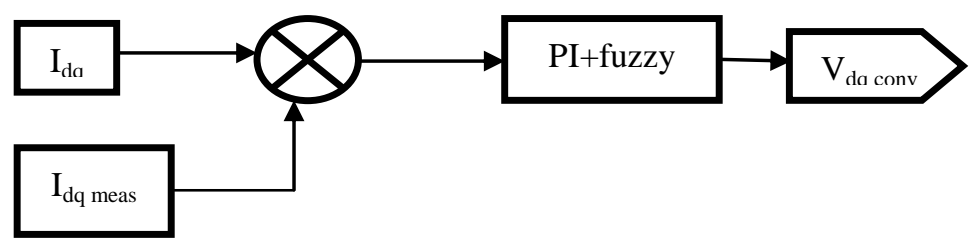

Fig. 5. Current regulation

By using the PI regulator direct and quadrature currents $\left(I_{d q}\right)$ are converted into a voltage $\left(V_{d q}\right)$. Fig. 5 shows the current regulation. This is the modulation waveform given to pulse width modulation. This converter controls the voltage at the connecting point of inverter and grid.

\section{PI and Fuzzy-PI based Current Regulator}

The PI controller is chosen over the PID controller as the parameters used for tunning is less. The equation of a PI controller for current regulation is given below.

Error Output $(t)=$

$$
K_{\text {hp }}\left(I_{d q}{ }^{*}-I_{d q}\right)+K_{\text {hi }} \int\left(I_{d q}{ }^{*}-I_{d q}\right) d t
$$

Where,

$$
\begin{aligned}
& I_{d q} * \text { - reference current } \\
& I_{d q} \text { - measured current, }
\end{aligned}
$$

The difference between both the currents produces the error. This error is minimized by the PI controller. The voltage output is the minimized error proposed by the controller.

Here,

Kkp - proportional constant

Kki -integral constant.

The parameters Kkp \& Kki are tuned by manual tuning methods.

The block diagram shows the PI controller with the fuzzy logic hybrid. Fig. 6 shows the regulated current by using the fuzzy-PI. The rules of the fuzzy logic are programmed by analysing the error characteristic of the PI controller performances.

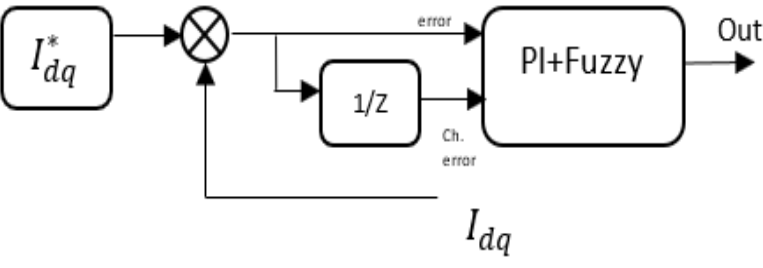

Fig. 6.Current regulation based on hybrid fuzzy-PI

The hybrid controller of PI -Fuzzy controller is implemented to generate the direct and the quadrature current reference for the controller which is shown in Figure 6. The error and the change in error of the reference and the actual dq component of the current is taken as the input to the PI Fuzzy controller.

Table- I: Fuzzy Rules of the Current Controller

\begin{tabular}{|l|l|l|l|}
\hline $\begin{array}{l}\text { err } \\
\text { change } \\
\text { in err }\end{array}$ & Low & Medium & High \\
\hline Low & Low & High & Medium \\
\hline Medium & Low & High & High \\
\hline High & Medium & Low & Medium \\
\hline
\end{tabular}

The Fuzzy logic controller in the hybrid contoller has three membership functions for both the input variables error and change in error. They are low, medium and high. The Fuzzy logic controller with triangular membership function is generated for both the variables and the results are obtained based on the following fuzzy rules which is the $3 \mathrm{X} 3$ fuzzy rules as defined in the Table I.

\section{RESULTS AND DISCUSSION}

The simulation of PV connected to the grid is done and the parameters of the simulations are given in the table. The PV is connected with the boost converter and the perturb and observe algorithm. The constant voltage is maintained at the point of DC-link. Then the DC voltage is converted to AC voltage. By using the converter. Then the low voltage is stepped up to grid voltage. Then the synchronization controller helps to send the power to grid. Under the synchronization control, the current controller is connected with PI or FUZZY-PI. Then the results are analyzed as given below.

The steady state power after the initial transients is evident in the figure 7(a). The steady state power graph of both the traditional PI and the hybrid Fuzzy-PI controller is depicted in Figure 7(a) while the enlarged comparison of the power curve shows a stable power from the hybrid controller which is advantageous and reduces the power oscillations which are evident in Figure 7(b). Even the average power is noticeably increased while the hybrid controller is utilized. 


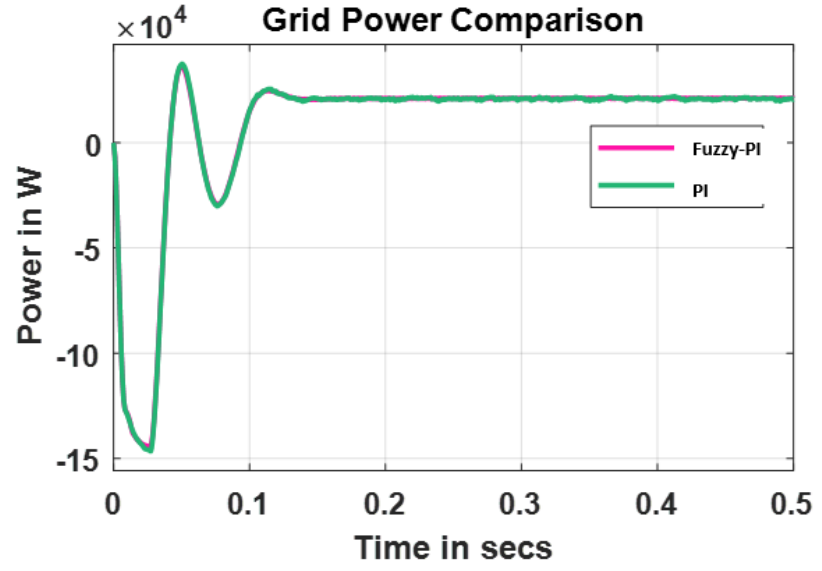

(a)

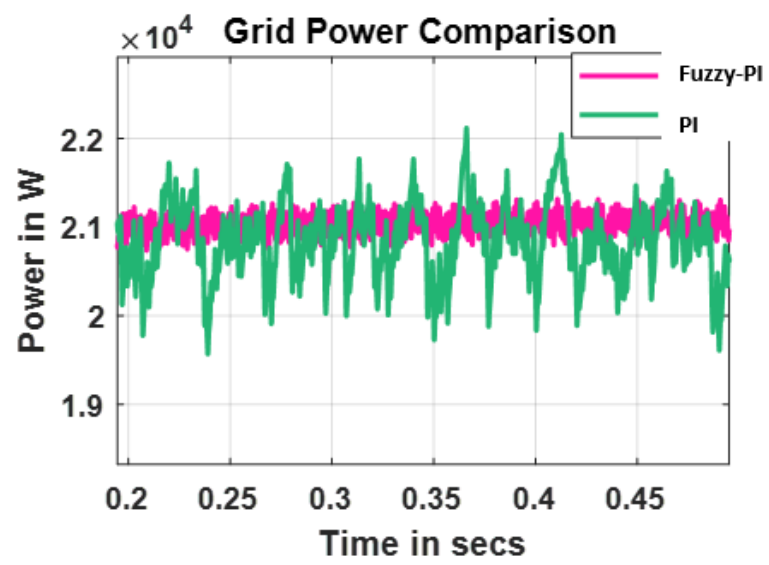

(b)

Fig. 7.Grid Power Delivered with PI and Fuzzy-PI Controller

The steady state DC link voltage obtained as obtained from both the PI and the Fuzzy-PI controller is shown in Figure 8 (a) and (b). The desired voltage of $900 \mathrm{~V}$ at the DC link is obtained with very little oscillation while hybrid method like the Fuzzy-PI is implemented while higher oscillations are evident in the PI controller implementation. Figure 8(a) depicts both the transient and the steady state DC link voltage . While Figure 8 (b) shows the Enlarged view of fig 8(a) at the steady state range of the DC link voltage..

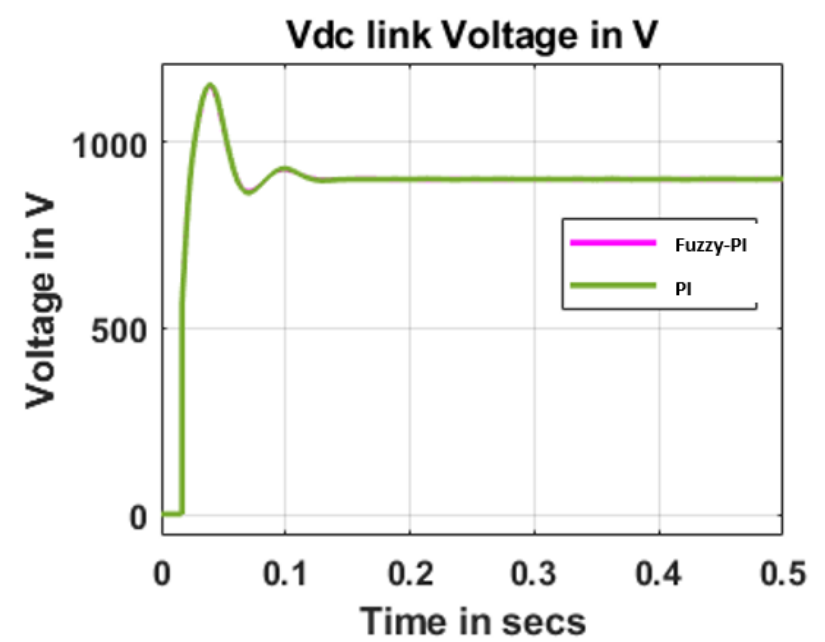

(a)

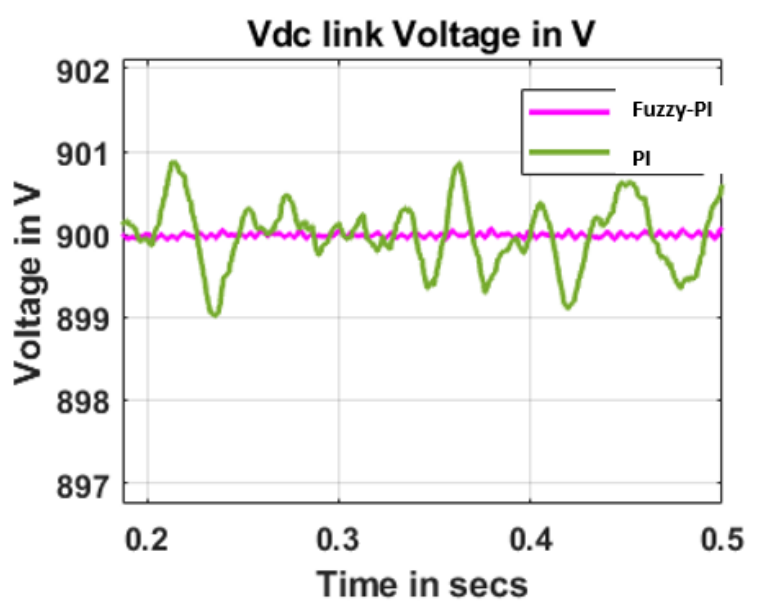

(b)

Fig. 8.DC link Voltage with PI and Fuzzy -PI controller

The PV power from the PV arrays which is fed to the grid for integration is evident in Figure 9 (a) comparing both PI and Fuzzy-PI..

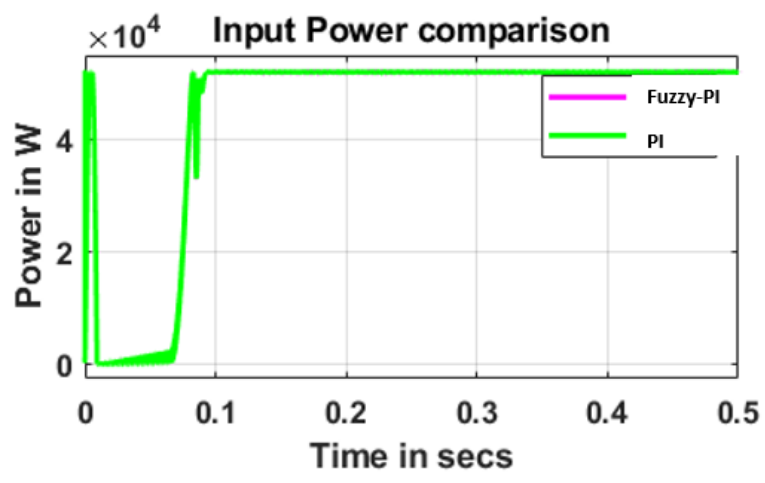

(a)

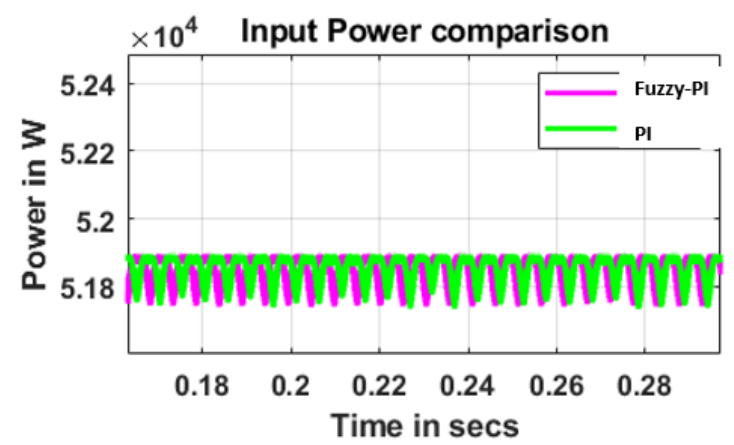

(b)

Fig. 9.Input Power from PV array

While Figure 9 (b) shows the Enlarged view of fig 9 (a) showing very little variation in the Solar power with both the controller compared

Published By:

Blue Eyes Intelligence Engineering 


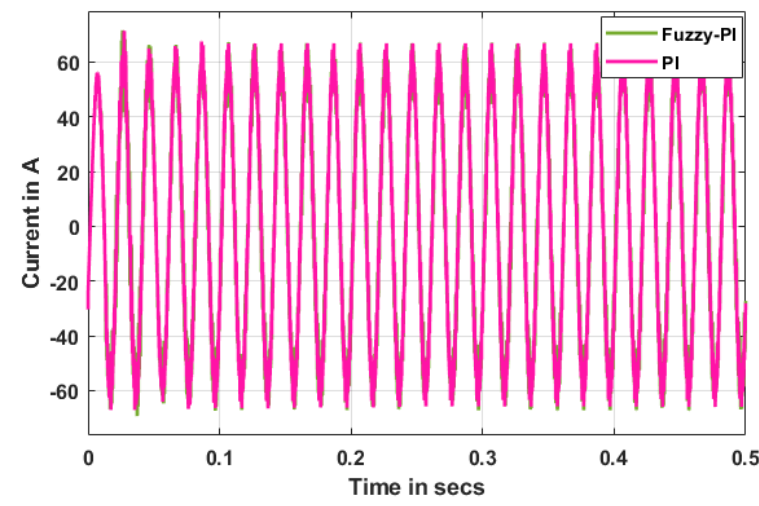

(a)

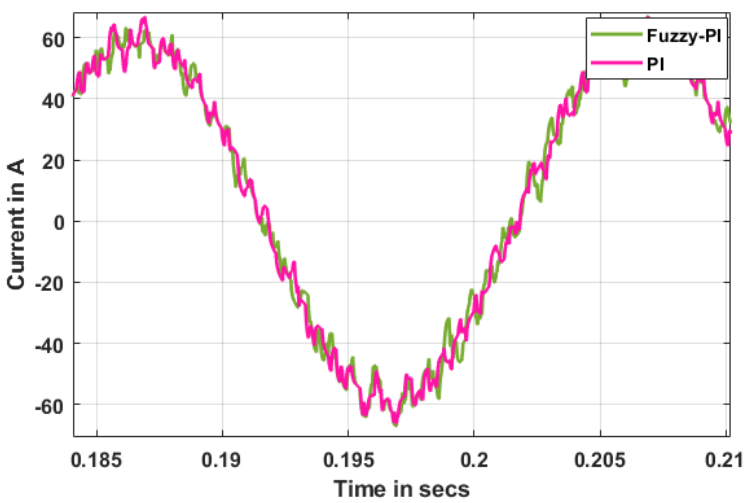

(b)

Fig. 10. Phase A grid Current at LV side

Figure 10 (a) shows the Grid current at phase A measured at LV side comparison with PI and Fuzzy-PI. Figure 10 (b) shows the Enlarged view of figure 10 (a). the current ripple differences can be seen clearly that the Fuzzy-PI gives lesser oscillations in the current.

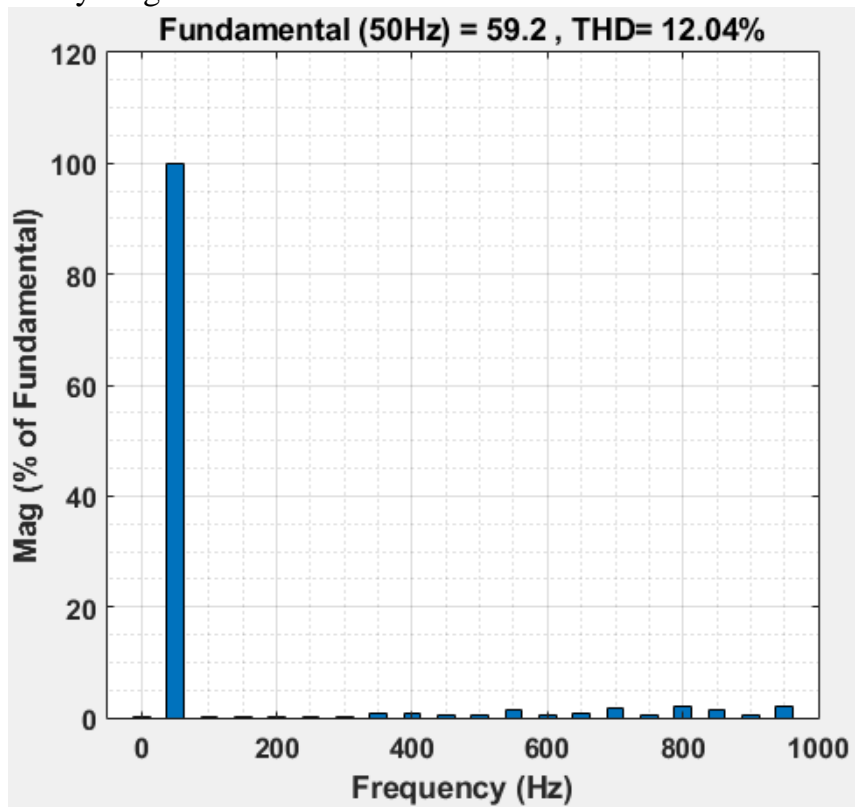

Fig. 11. THD of Grid Current with PI controller

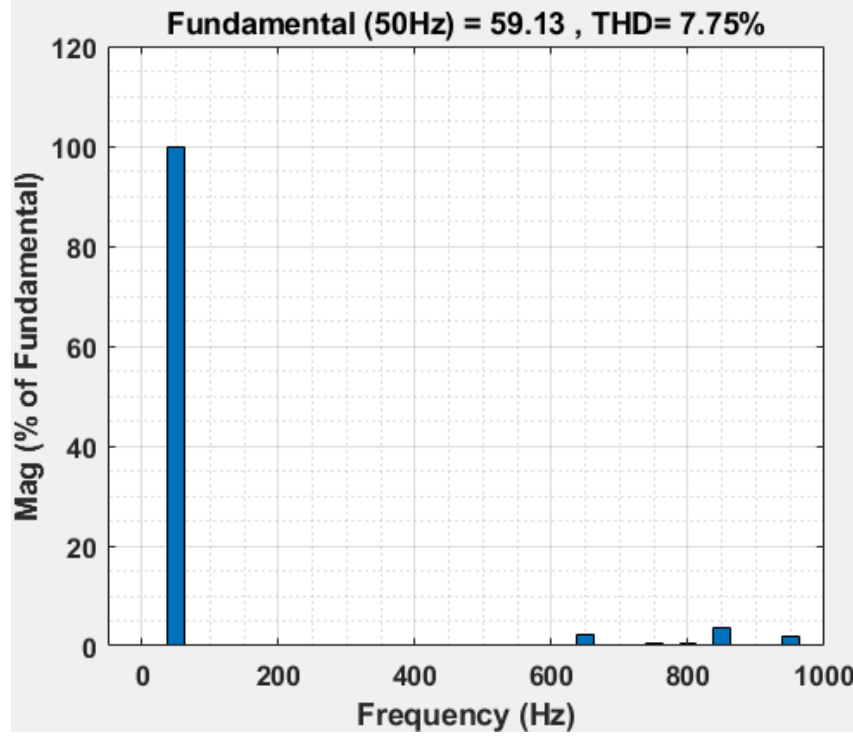

Fig. 12. THD of Grid Current with Fuzzy-PI controller

The ripple content also is very less compared to PI. Figure 11 shows the THD of the PI-based current controller. Figure 12 shows the THD of Fuzzy-PI based current controller. Fuzzy-PI controller gives lesser THD the PI controller gives higher THD values The specifications of the PV array, Boost converter involved, Transformer and the Grid which includes the power,voltage and current ratings are as shown in TableII.

Table- II: Simulation Parameters

\begin{tabular}{|c|c|c|}
\hline Components & Parameters & Values \\
\hline \multirow{7}{*}{ PV array } & Product ID & $\begin{array}{c}\text { SunPower SPR-305- } \\
\text { WHT }\end{array}$ \\
\hline & $\mathrm{V}_{\mathrm{mpp}}$ & $54.7 \mathrm{~V}$ \\
\hline & $I_{m p p}$ & $5.58 \mathrm{~A}$ \\
\hline & $\mathrm{V}_{\mathrm{oc}}$ & $64.2 \mathrm{~V}$ \\
\hline & $\mathrm{I}_{\mathrm{sc}}$ & $5.92 \mathrm{~A}$ \\
\hline & Number of panels in series & 5 \\
\hline & $\begin{array}{c}\text { Number of panels in } \\
\text { parallel }\end{array}$ & 34 \\
\hline \multirow{3}{*}{ Boost converter } & Inductor & $5 \mathrm{mH}$ \\
\hline & capacitor & $12000 \mathrm{uF}$ \\
\hline & frequency & $5 \mathrm{kHz}$ \\
\hline \multirow{4}{*}{ Transformer } & kVA rating & 100 \\
\hline & Low side voltage & $415 \mathrm{~V}$ \\
\hline & High side voltage & $11 \mathrm{kV}$ \\
\hline & Frequency & $50 \mathrm{~Hz}$ \\
\hline \multirow{3}{*}{ Grid } & MVA rating & 100 \\
\hline & Voltage & $11 \mathrm{kV}$ \\
\hline & Frequency & $50 \mathrm{~Hz}$ \\
\hline
\end{tabular}

The results obtained after the grid synchronization infers that the Fuzzy -PI controller is able to affect the controlling of the power delivery, oscillations, and the THD at the grid side power. 


\section{CONCLUSION}

Matlab based simulation of the PV generator synchronization is carried out on a $11 \mathrm{KV}$ power system with the dq controller for synchronization. The PI and the Fuzzy-PI controller for power delivery performance improvement is dealt in detail. The simulations carried out for the PI controller and fuzzy-PI controller for the current regulation in the grid. According to the analysis, hybrid controller performances are better comparatively. The results obtained after the grid synchronization infers that the Fuzzy -PI controller is able to affect the controlling of the power delivery, oscillations, and the THD at the grid side power.

\section{REFERENCES}

1. R. Guerrero-Lemus, \& et.al. "A simple big data methodology and analysis of the specific yield of all PV power plants in a power system over a long time period", Renew. Sustain. Energy Rev. 2019, 107, $123-132$.

2. Han, P, Lin, Z \& et.al. "A Survey on Equivalence Modeling for Large-Scale Photovoltaic Power Plants". Energies 2018, 11, 1463.

3. la Parra, I \& et.al. "PV performance modeling: A review in the light of quality assurance for large PV plants", Renew. Sustain. Energy Rev. 2017, 78, 780-797.

4. Mehrasa, \& et.al, "Control technique for the operation of grid-tied converters with high penetration of renewable energy resources", Electr. Power Syst. Res. 2019, 166, 18-28.

5. Mehrasa, M., \& et.al, "Virtual Inertia, and Mechanical Power-Based Control Strategy to Provide Stable Grid Operation under High Renewables Penetration". Appl. Sci. 2019, 9, 1043-1058.

6. Wang, D., \& et.al. "Coordinated Dispatch of Virtual Energy Storage Systems in LV Grids for Voltage Regulation", IEEE Trans. Ind. Inform. 2018, 14, 2452-2462.

7. Refaat, S.S. \& et.al. “A. Impact of a grid-tied large-scale photovoltaic system on dynamic voltage stability of electric power grids", IET Renew. Power Gener. 2018, 12, 157-164

8. Y. Chaibi, A. \& et.al. "Annual performance analysis of different maximum power point tracking techniques used in photovoltaic systems," Protection and Control of Modern Power Systems, vol. 4, no. $1,2019$.

9. Hanan A. Mosalam, \& et.al, "Fuzzy logic control for a grid-connected PV array through Z-source-inverter using maximum constant boost control method", Ain Shams Engineering Journal, Volume 9, Issue 4, 2018, Pages 2931-2941.

10. Harsha Anantwar, \& et.al, "Fuzzy self-tuning PI controller based inverter control for voltage regulation in off-grid hybrid power system”, Energy Procedia, Volume 117, 2017, Pages 409-416.

11. H. W. D. Hettiarachchi, "Review of Applications of Fuzzy Logic in Multi-Agent-Based Control System of AC-DC Hybrid Microgrid", IEEE Access, 2018.

\section{AUTHORS PROFILE}

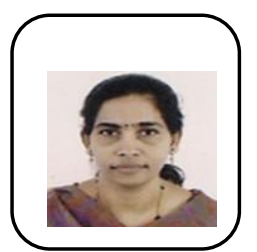

Mrs. B.G. Sujatha obtained her Bachelor's degree in Electrical and Electronics from University of Mysore, India. Then she obtained her master's degree in power and energy systems from University of Mangalore, India, and doing $\mathrm{PhD}$ in Electrical Engineering at Jain University, Bangalore, India. Currently, she is Associate Professor in the Department of Electrical and Electronics at Cambridge Institute of Technology, Bangalore. Her specializations include power systems, renewable Energy sources. Her current research interests are solar energy technology, distributed generation, and power system simulation.

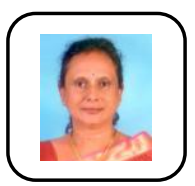

Dr. G.S. Anitha received the B.E. degree from the Bangalore University, India, in 1983, the M.E degree from the Bangalore University, in 1988, and the Ph.D. degree from the Avinashilingam women's University, Coimbatore, India, in 2010. From 2007 to 2011, she worked as Assistant Professor in the Department of Electrical and
Electronics at R.V. College of Engineering, Bangalore. She is currently working as Associate Professor in the Department of Electrical and Electronics Engineering at RV College of Engg, Bangalore. Her research interests include renewable energy sources, power electronics and power systems. She is a reviewer for the Journal of Electrical Engineering \& Technology, various International journals including international conferences. 